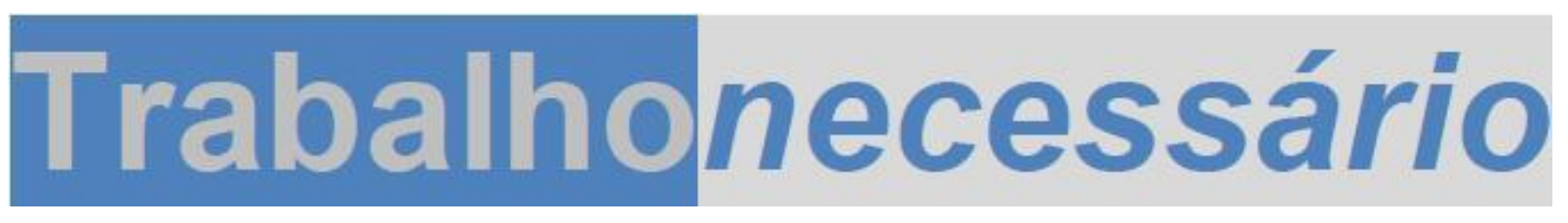

Issn: 1808 - 799X

ano 12, no $18-2014$

Ensaio

\title{
A CRISE ECONÔMICA NO MODO DE PRODUÇÃO CAPITALISTA: UMA ANÁLISE, À LUZ DE MARX
}

\author{
Remo Moreira Brito Bastos ${ }^{1}$
}

\section{Resumo}

$\mathrm{Na}$ contramão de interpretações existentes no meio marxista de que Marx não teria sintetizado uma teoria explícita e sistematizada sobre as crises no capitalismo, o que representaria uma lacuna em sua obra, o ensaio busca trazer à luz a problemática da crise no modo de produção capitalista, a partir do peculiar referencial teórico-metodológico daquele autor, no qual se insere o caráter imanente e dialético do conceito de crise. Procurar-se-á, fundamentado em $O$ Capital, recuperar as situações e configurações potenciais suscetíveis de desencadear crises naquele modo de produção, e mostrar que aquelas, na verdade, são constitutivas deste e, apesar de seu caráter ineliminável, atuam de modo funcional ao sistema, propiciando a este a passagem de um ciclo de distúrbios econômicos e sociais para o ciclo posterior, de elevada produção, emprego e demanda de produtos industrializados. A exposição perpassa, portanto, os três livros daquela obra magna, trazendo à tona os aspectos e as instâncias do processo de acumulação de capital relevantes para a elucidação das crises, salientando ainda os pressupostos metodológicos com os quais Marx trabalha em cada um dos livros.

Palavras-chave: Crise; capitalismo; Karl Marx.

\footnotetext{
${ }^{1}$ Servidor Público Federal (IBGE, Analista). Mestrando em Educação na Universidade Federal do Ceará (UFC), linha de pesquisa Trabalho e Educação. Pós-graduado em Administração Pública pela Faculdade Gama Filho (FGF-RJ) e graduado em Administração pela Faculdade Integrada do Ceará. remomoreira@gmail.com
}

TrabalhoNecessário - www.uff.br/trabalhonecessario; Ano 12, № 18/2014. 


\title{
Trabalhonecessário
}

Issn: 1808 - 799X

ano 12 , no $18-2014$

\begin{abstract}
This paper follows the opposite of some existing Marxist interpretations, that Marx would not have synthesized an explicit and systematic theory of crises in capitalism, which would represent a gap in his work in relation to the theme. It attempts to bring to light the issue of crisis in the capitalist way of production, from that author's peculiar theoretical and methodological framework, which incorporates the immanent and dialectical character of the concept of crisis. Based on Capital, this research will retrieve situations and potential configurations capable of triggering crises in that mode of production and show that those, indeed, are constitutive of this, and despite their ineradicable character, they act functionally to system, leading it from an economic and social disorder cycle to the subsequent cycle, of high production, employment and demand for manufactured products. This paper permeates all three books of his masterpiece, bringing out aspects and instances of the accumulation of capital process relevant for the elucidation of the crisis, besides pointing out the methodological assumptions with which Marx works in each of his books.
\end{abstract}

Key words: Crisis; capitalism; Karl Marx

\section{Introdução}

O presente trabalho busca proceder a uma caracterização de crise no modo de produção capitalista, a partir do entendimento de Karl Marx. Para isso, pretende-se apreender o entendimento marxiano sobre as crises a partir da dinâmica do capital esboçada em sua obra magna, O Capital (Marx, 2011a, 2011b, 2003, 2008)

Tornou-se lugar comum nos meios do marxismo o entendimento de que Marx não sintetizou uma teoria explícita e sistematizada sobre as crises no capitalismo, o que representaria uma lacuna em sua obra, no que se refere à temática. A ausência de livros ou mesmo capítulos / seções versando especificamente sobre o assunto ajuda a robustecer tal posição, contribuindo 


\section{Trabalhonecessário}

Issn: 1808 - 799X

ano 12, no $18-2014$

ainda, para isso, o fato de Marx ter programado um sexto livro de O Capital contemplando exatamente a matéria de que se trata. ${ }^{2}$

Não obstante, existe um posicionamento divergente ${ }^{3}$ do supra mencionado, com o qual concorda o autor do presente ensaio, que entende que Marx não somente contemplou as crises no seu estudo do modo de produção capitalista, mas que essas possuem o estatuto de mecanismo constitutivo daquele sistema, intercalando as diferentes fases do ciclo econômico. Ademais, alguns estudiosos chegam mesmo a salientar o seu papel purgatório e saneador, capaz de restabelecer as condições favoráveis para o retorno do processo de acumulação do capital.

Procurar-se-á mostrar como Marx, nos livros Primeiro e Terceiro (este tendo o Segundo como pano de fundo, que estabelece as bases do processo de circulação do capital, o que será aprofundado naquele) de O Capital, analisa e explica a crise no referido modo de produção, salientando seu caráter ineliminável, sua essência e seus elementos constitutivos.

O Capital, como não poderia deixar de ser, até por se tratar de sua obra prima, a síntese sistematizada e o coroamento de um árduo trabalho de pesquisa de pelo menos quinze anos (de 1951, quando se instala em Londres, exilado, a 1966, quando conclui a redação definitiva do Livro Primeiro) no que o próprio autor denominou como Crítica da Economia Política, contém a análise marxiana mais acurada e, pode-se dizer, definitiva, em sua obra, da crise no $\mathrm{MCP}^{4}$, distribuída nos três livros que o compõem.

Entretanto, conforme salientado, a teoria da crise não está explicitada de forma clara em qualquer livro ou capítulo de $O$ Capital. Não obstante, entende o autor do presente trabalho que leitura acurada da obra permite apreender diversos elementos analíticos que contribuem para dar contorno à temática.

2 Compartilham desse entendimento intelectuais marxistas como Ernest Mandel, Roman Rosdolsky, Paul Sweezy, dentre outros.

3 Jadir Antunes e Hector Benoit são alguns dos autores que esposam esse entendimento, o que o fazem de forma mais explícita em sua obra conjunta ANTUNES, BENOIT, 2009.

${ }^{4}$ Doravante, no presente trabalho, este acrônimo substituirá a expressão modo capitalista de produção. 


\section{Trabalhonecessário}

Issn: 1808 - 799X

ano 12, no $18-2014$

Para Marx, não havia lacuna alguma em $O$ Capital no que se refere às crises do MCP, simplesmente porque essas são constitutivas do próprio sistema, desempenhando papel fundamental na alternância dos ciclos de reprodução do capital. Nos três livros, elas estão presentes. De forma pura e abstrata no primeiro e no segundo livro, nos quais o autor delineia o arcabouço teórico do sistema capitalista ainda a partir de pressupostos metodológicos como ausência de concorrência, unidade de capitais e outros que possibilitem seu estudo. No terceiro livro, de forma mais cabal, agora, como síntese das contradições indicadas no plano abstrato nos dois livros anteriores, e passando a considerar a existência de múltiplos capitais e a concorrência entre eles.

Portanto, há que se compreender o caráter imanente e dialético do conceito de crise, em $O$ Capital, e não confundi-lo com as manifestações empíricas daquela, explicitadas nos ciclos econômicos. Desde o primeiro livro, Marx já delineia claramente as possibilidades de crises, ao apontar as contradições entre trabalho concreto e trabalho abstrato, valor de troca e valor, e produção e realização da mais-valia.

\section{Possibilidades de crise no Livro Primeiro}

No Livro Primeiro, ao tratar da esfera da produção, na qual tem lugar a produção da mercadoria prenhe de mais valor, extraído do trabalho não pago ao seu real produtor, o trabalhador, Marx explora, além das mencionadas no parágrafo anterior, as contradições das determinações existentes no dinheiro e na mercadoria, que têm lugar na circulação simples. Mostra que um produtor, no MCP, não pode escolher entre vender ou não o seu produto, pois este somente tem para ele um valor de uso, a saber, o de ser portador de valor de troca e, assim, meio para aquisição de outro valor de uso que the convenha. Aparece aí a primeira possibilidade de crise: se a mercadoria não for vendida, todo o processo de produção é interrompido, como ilustra Marx no trecho abaixo. 


\section{Trabalhonecessário}

Issn: 1808 - 799X

ano 12 , no $18-2014$

[...] Ninguém pode vender, sem que alguém compre. Mas ninguém é obrigado a comprar imediatamente, apenas por ter vendido. A circulação rompe com as limitações de tempo, de lugar e individuais, impostas pela troca de produtos, ao dissociar a identidade imediata que, nesta última, une a alienação do produto próprio e a aquisição do alheio, gerando a antítese entre venda e compra. Dizer que esses atos antitéticos, independentes entre si, possuem uma unidade interior equivale a dizer que essa unidade interior transparece através de antíteses externas. Se essa independência exterior dos dois atos - interiormente dependentes por serem complementares - prossegue se afirmando além de certo ponto, contra ela prevalece, brutalmente, a unidade, por meio de uma crise. A contradição imanente à mercadoria, que se patenteia na oposição entre valor-de-uso e valor, no trabalho privado, que tem, ao mesmo tempo, de funcionar como trabalho social imediato, no trabalho concreto particular, que, ao mesmo tempo, só vale como trabalho abstrato geral, e que transparece na oposição entre a personificação das coisas e a representação das pessoas por coisas, - essa contradição imanente atinge formas completas de manifestar-se nas fases opostas da metamorfose das mercadorias. Essas formas implicam a possibilidade, mas apenas a possibilidade das crises. Para a conversão dessa possibilidade em realidade é mister todo um conjunto de condições, que não existem ainda, do ponto de vista da simples circulação das mercadorias. (MARX, 2011a, p. 140) (grifos do autor)

Precisamente neste ponto, na possibilidade de a mercadoria não conseguir realizar sua metamorfose em dinheiro, surge, então, a primeira possibilidade de crise no MCP, uma possibilidade ainda formal e abstrata, decorrente da contradição entre o valor de uso e o valor corporificado na mercadoria. Há que se observar que se a troca entre os produtores fosse direta, sem a intermediação do dinheiro, não haveria a necessidade dessa metamorfose da mercadoria e, consequentemente, nem a possibilidade de crise. $O$ que engendra essa primeira possibilidade de crise é a necessidade de a mercadoria se desdobrar externamente em mercadoria e dinheiro, e a possibilidade deste se autonomizar diante daquela. Os produtores ficam na dependência dos possuidores de dinheiro, que representa o equivalente universal e forma superior de riqueza, francamente cambiável por qualquer outra mercadoria.

Outra possibilidade de crise reside na eventualidade de insolvência generalizada entre os agentes econômicos, quando o crédito passa a ter papel proeminente nas transações. Nas palavras do próprio Marx,

[...] Com o desenvolvimento da circulação das mercadorias, vão aparecendo as condições em que a alienação da mercadoria se separa, por um intervalo de tempo, da 


\title{
Trabalhonecessário
}

Issn: 1808 - 799X

ano 12 , no $18-2014$

\begin{abstract}
realização de seu preço. [...] O vendedor torna-se credor, o comprador, devedor. A metamorfose da mercadoria ou o desenvolvimento de sua forma valor assume então novo aspecto, e, em consequência, o dinheiro adquire nova função. Ele se torna meio de pagamento. (MARX, 2011a, p. 161-2)

[...]

Voltemos à esfera da circulação das mercadorias. Cessou o aparecimento simultâneo dos equivalentes, mercadoria e dinheiro, nos dois pólos de processo de venda. 0 dinheiro passa a exercer duas funções: Primeiro, serve de medida de valor, ao determinar-se o preço da mercadoria. O preço contratualmente fixado mede a obrigação do comprador, ou a soma de dinheiro a qual em data estabelecida. Segundo, o dinheiro serve de meio ideal de compra. Embora só exista na promessa do comprador, motiva a transferência da mercadoria. $O$ dinheiro só entra realmente em circulação na data do pagamento, quando passa das mãos do comprador para as do vendedor. [...]

[...]

O comprador converte dinheiro em mercadoria, antes de ter convertido mercadoria em dinheiro, ou realiza a segunda metamorfose [da mercadoria] antes da primeira. A mercadoria do vendedor circula, mas realiza o preço apenas sob a forma de um direito sobre o dinheiro a receber. É objeto de consumo de outrem antes de converter-se em dinheiro. Só posteriormente sucede a primeira metamorfose. (MARX, 2011a, p. 162-3)
\end{abstract}

Observe-se que, a partir de então, o dinheiro não mais aparece como um simples meio de circulação, que viabiliza a troca de duas mercadorias, mas como o fim, em si mesmo, da transação. Vender a mercadoria para quitar a dívida passa a ser o objetivo final do processo. Assim, se o vendedor não conseguir vender a mercadoria, não conseguirá quitar sua dívida com o credor. Alastrandose essa dificuldade entre vários vendedores, instaura-se a crise e a falência não somente desses, mas também de outros produtores que a eles estão ligados por negócios firmados e que deles dependem.

O imperativo estrutural do MCP da busca desenfreada de mais-valia relativa constitui outra via de instauração de crise. Como o incremento dessa modalidade de mais-valia leva à diminuição da quantidade de trabalho necessário, decresce necessariamente $o$ valor da força de trabalho $e$, consequentemente, o poder de consumo da classe trabalhadora, criando uma cisão entre produção e consumo.

O desenvolvimento da produtividade do trabalho na produção capitalista tem por objetivo reduzir a parte do dia de trabalho durante a qual o trabalhador tem de trabalhar para si mesmo, justamente para ampliar a outra parte durante a qual pode trabalhar gratuitamente para o capitalista. (MARX, 2011a, p. 372) 


\section{Trabalhonecessário}

Issn: 1808 - 799X

ano 12 , no $18-2014$

Na sétima seção da mesma obra, Marx passa a analisar, ainda em elevado grau de abstração (a qual só abandonará no Livro Terceiro), o processo de acumulação de capital, ou seja, o processo de conversão da mais-valia neste. Não se deve olvidar, retomando o que foi sinalizado no início da presente exposição, que o autor ainda não pode, no primeiro e no segundo livro, desenvolver a análise da crise em sua forma empírica, mais acabada, simplesmente porque isto impediria a construção do modelo teórico que tenta explicá-la, com todos os seus determinantes. É como se Marx estivesse em um laboratório, tendo que trabalhar com elementos em estado puro e isolados dos efeitos desestabilizadores presentes no ambiente real, que dificultariam a observação das características e das relações entre aqueles.

Dado que o capitalista acumula capital pela conversão de sua renda neste, diminuindo, assim, a participação relativa do consumo em relação à produção social (o que, como já aludido anteriormente, também acontece com a classe trabalhadora, porém, por razões opostas, ou seja, por aquela ter sua capacidade de consumo premida pelos determinantes do capital), põe-se aí nova possibilidade de crise, ao se separarem violentamente produção e consumo de riqueza. Com uma composição orgânica cada vez maior, maior também será progressivamente sua escala, ao passo que a capacidade de absorção da produção, por parte da classe trabalhadora, tende a decrescer, relativamente. llustra Marx:

Outro importante fator para a acumulação é o grau de produtividade do trabalho social. Com a produtividade do trabalho, aumenta a quantidade produzida em que se corporifica determinado valor e, portanto, dada magnitude de mais-valia. Não se alterando a taxa da mais-valia e mesmo diminuindo, desde que sua queda seja menos veloz que a ascensão da produtividade do trabalho, aumenta a quantidade de produto excedente. Não se alterando a proporção em que este se divide em renda e capital adicional, pode então o consumo do capitalista aumentar sem decréscimo do fundo de acumulação. A magnitude proporcional do fundo de acumulação pode [até mesmo] aumentar à custa do fundo de consumo, enquanto o barateamento das mercadorias põe à disposição do capitalista a mesma quantidade anterior, ou maior, de meios de fruição. Mas, conforme já vimos, juntamente com a produtividade crescente do trabalho ocorrem o barateamento do trabalhador e, em consequência, uma taxa crescente de mais-valia, mesmo quando se eleva o salário real. Este nunca sobre na mesma 


\title{
Trabalhonecessário
}

Issn: 1808 - 799X

ano 12 , no $18-2014$

proporção da produtividade do trabalho. (MARX, 2011b, p. 703) (grifos e colchete do autor).

Na segunda seção do capitulo XXIII, Marx trata, dentre outros aspectos, da acumulação de capital, de sua concentração e da centralização de pulverizados capitais individuais menores "nas mãos" de poucos gigantescos grupos capitalistas. Explica o autor que a concentração nada mais é do que o aprofundamento do processo de acumulação de um capital individual em termos de escala e magnitude de meios de produção, com seu crescente aumento da composição orgânica, tornando-se cada vez maior a sua parte constante em relação à variável. Ver-se-á, na sequência da exposição, que esses dois processos levam ao aumento exponencial do exército de reserva de mão-de-obra, fator potencializador de crises quando esse incremento explode em proporções que impedem a adequada realização da mais-valia produzida.

Já a centralização reflete a força de atração que os capitais maiores exercem sobre os menores, suprimindo a autonomia desses, consubstanciando 0 que Marx denomina

\begin{abstract}
a expropriação do capitalista pelo capitalista, transformação de muitos capitais pequenos em poucos capitais grandes. Esse processo se distingue do anterior porque pressupõe apenas alteração na repartição dos capitais que já existem e estão funcionando; seu campo de ação não está, portanto, limitado pelo acréscimo absoluto da riqueza social ou pelos limites absolutos da acumulação. O capital se acumula aqui nas mãos de um só, porque escapou das mãos de muitos noutra parte. Esta é a centralização propriamente dita, que não se confunde com a acumulação e a concentração. (MARX, 2011b, p. 729)
\end{abstract}

Como conseqüência, alem da ruína dos pequenos capitalistas, a combinação dos processos de concentração e centralização de capital lança massas inteiras de trabalhadores no exército industrial de reserva de mão-deobra, derrubando, drasticamente, a demanda de produtos e aumentando mais ainda o fosso entre a produção e o consumo social, consubstanciando, assim, mais uma possibilidade de crise no sistema. Outro efeito nefasto desses processos diz respeito à perda do histórico e necessário equilíbrio entre produção e distribuição, um dos pilares de sustentação básicos do MPC. 


\section{Trabalhonecessário}

Issn: 1808 - 799X

ano 12, no $18-2014$

Perceba-se, não obstante, o caráter funcional dessa superpopulação de reserva de mão-de-obra para o capital. Além de a mesma servir de manancial de força produtiva ao qual pode aquele recorrer nas fases de expansão da produção, conforme salienta o próprio Marx ${ }^{5}$, atua ainda essa massa de desempregados na regulação do preço da mão-de-obra, pressionando o valor dos salários para baixo, penalizando, assim, tanto os trabalhadores empregados como os desempregados.

Fechando o Livro Primeiro, com o famoso capitulo XXIV - $A$ assim chamada acumulação originária, Marx traz a síntese definitiva e concomitante princípio fundamental de todas as contradições que o capital engendra, muitas das quais abordadas no presente ensaio, e outras contempladas nos três volumes de O Capital e em outros escritos daquele autor.

Com a análise da acumulação originária, desvela-se o princípio que fundamenta todas as contradições do capital, desde as mais simples às mais complexas: a separação do trabalhador frente aos meios de produção. Sem esta, não existe MCP, e ao mesmo tempo todas as crises que a acumulação de capital engendra decorrem, em ultima instância, dessa fundamental expropriação. A própria acumulação de capital tem como pressuposto sine-quanon, essa separação.

A irreconciliável oposição entre capital e trabalho mina, desde o nascedouro do MCP, seu harmônico funcionamento, e se reflete nas violentas batalhas travadas na luta de classes, nesses dois séculos e meio de antagonismo entre as duas classes fundamentais desse modo de produção.

Ao negar, por meio da concorrência e dos grandes monopólios, a propriedade, não somente aos trabalhadores mas até mesmo aos membros mais débeis de sua própria classe, o capital, de acordo com Marx, chega finalmente ao

\footnotetext{
5 "Não basta à produção capitalista a quantidade de força de trabalho disponível, fornecida pelo incremento natural da população. Para funcionar à sua vontade, precisa ela de um exército industrial de reserva que não dependa desse limite natural." (MARX, 2011b, p. 738)
} 


\title{
Trabalhonecessário
}

Issn: 1808 - 799X

ano 12 , no $18-2014$

ápice de seu processo de exacerbação de contradições - a negação da negação sua derrocada final, pelos expropriados, e a vitória da revolução operária.

\begin{abstract}
Soa a hora final da propriedade particular capitalista. Os expropriadores são expropriados.

O modo capitalista de apropriar-se dos bens, decorrente do modo capitalista de produção, ou seja, a propriedade privada capitalista, é a primeira negação da propriedade privada individual, baseada no trabalho próprio. Mas a produção capitalista gera sua própria negação, com a fatalidade de um processo natural. É a negação da negação. Esta segunda negação não restabelece a propriedade privada, mas a propriedade individual tendo por o fundamento a conquista da era capitalista: a cooperação e a posse comum do solo e dos meios de produção gerados pelo próprio trabalho.

A transformação da propriedade particular esparsa, baseada no trabalho próprio dos indivíduos, em propriedade privada capitalista constitui, naturalmente, um processo muito mais longo, mais duro e mais difícil que a transformação em propriedade social da propriedade capitalista que efetivamente já se baseia sobre um modo coletivo de produção, Antes, houve a expropriação da massa do povo por poucos usurpadores, hoje, trata-se da expropriação de poucos usurpadores pela massa do povo. (MARX, 2011b, p. 877)
\end{abstract}

\section{Possibilidades de crise nos livros Segundo e Terceiro}

Se no Livro Primeiro Marx focou no processo de produção da mais-valia, no segundo se dedicará a analisar as contradições do processo de circulação e realização daquela. Isto será empreendido ainda nas mesmas condições de abstração com as quais o autor trabalha no livro anterior, muito embora agora, com um ponto de partida mais determinado, pois parte da circulação do produto já como produto do capital, e não de uma abstrata circulação simples de mercadorias, como o fazia no Livro Primeiro. Dessa forma, defrontam-se agora no mercado trabalhadores, vendendo sua força de trabalho, e capitalistas comprando-a, agora com a mais-valia realizada, e não meros compradores e vendedores de mercadorias em geral.

Das três Partes que compõem o Segundo Livro, a primeira trata do processo de valorização do capital (ainda individual), desdobrando-o nas três formas funcionais de capital-dinheiro, capital produtivo e capital mercadoria, 


\section{Trabalhonecessário}

Issn: 1808 - 799X

ano 12, no $18-2014$

através das quais o capital flui continuamente, perpassando suas metamorfoses e seus respectivos ciclos, respectivamente correspondentes a cada forma.

$\mathrm{Na}$ interrupção do fluxo de capital, vislumbra-se mais uma possibilidade de crise, ou seja, na ocorrência de uma forma funcional não conseguir se converter na seguinte, com regularidade e tempos esperados, irrompem as condições propícias para a deflagração da crise. Em outras palavras: se o capital-dinheiro não conseguir converter-se em mercadoria, sob a forma de força de trabalho e meios de produção; se estes não se converterem em mercadoria prenhe de maisvalia, e se esta, por sua vez, não conseguir realizar o seu valor (e mais valor), através da venda; tudo isso no tempo médio esperado. Qualquer uma dessas ocorrências (ou melhor, não-ocorrências) coloca em risco a circulação do capital, asfixiando-o e impedindo sua imprescindível acumulação.

No entanto, é no Livro Terceiro que Marx analisa o capital enquanto pluralidade de capitais individuais, concorrentes entre si e com interesses divergentes e contraditórios, os quais constituem fatores potenciais de crises.

Nesse livro, as possibilidades de crises como expressões das contradições abstratas mais simples do capital serão definitivamente reveladas como insolúveis, nos marcos do MCP, e tendentes a explodir com crises inexoráveis, nos momentos finais desse modo de produção. Dentre aquelas contradições, é possível mencionar valor e valor de uso, trabalho concreto e trabalho abstrato, mercadoria e dinheiro, as quais são harmonizadas tão somente com finalidade metodológica nos dois primeiros livros, com vistas a uma exposição inteligível.

Precisamente na Parte Terceira do livro, Marx trata daquela que se constituiria na principal lei econômica tendencial do movimento do capital, "sem dúvidas a lei mais importante da economia política", como ele próprio afirmou nos Grundisse $^{6}$, a lei da queda tendencial da taxa de lucro, cuja essência consiste, basicamente, no seguinte.

\footnotetext{
6 “[...] Em todos os sentidos, essa é a lei mais importante da economia política moderna e a mais essencial para compreender as relações mais complicadas. [...]" (MARX, 2011, p. 626).
} 


\section{Trabalhonecessário}

Issn: 1808 - 799X

ano 12 , no $18-2014$

Todo capitalista, premido pela concorrência, precisa perseguir sempre ganhos de produtividade na produção, de forma a conseguir produzir mercadorias com o menor tempo de trabalho necessário possível, de forma a reduzir seus custos e vendê-las com maior margem de lucro. Um capitalista que, na tentativa de superar os concorrentes, conseguir desenvolver uma tecnologia inovadora a qual the permita produzir determinada mercadoria com uma produtividade inédita, portanto em um tempo de trabalho bem menor do que o amplamente praticado no mercado - o qual Marx designa tempo de trabalho socialmente necessário conseguirá, ao baixar o valor da mercadoria que produz, com o uso da nova tecnologia, e vendê-la pelo preço de mercado praticado quando ainda vige a antiga tecnologia ou, até mesmo, por um pouco menos, abocanhar, assim, uma mais-valia adicional.

[...] O capitalista, que emprega métodos melhores de produção, mas ainda não generalizados, vende abaixo do preço de mercado, mas acima de seu preço individual de produção; assim, eleva-se para ele a taxa de lucro, até que a concorrência desfaz essa vantagem [...]. (MARX, 2008, p. 304) ${ }^{7}$

Todavia, como mostra Marx, na citação supra, a supremacia tecnológica do capitalista inovador não perdura indefinidamente e, logo, a concorrência tem acesso à então inovadora tecnologia, generalizando-a no mercado e fazendo cair para todos os capitalistas o valor da mercadoria, seu preço de mercado e, consequentemente, a taxa média de lucro.

Observe-se que o que parecia salutar e lógico para cada capitalista individual (buscar inovações tecnológicas que melhorem a produtividade, incrementando, assim, a extração de mais-valia), resultou danoso para a classe capitalista como um todo (a queda da taxa média de lucro). Contudo, atente-se para a fórmula de lucro: I' = m / c + v (Marx, 2011b, p. 595), na qual $\boldsymbol{m}$ representa

\footnotetext{
${ }^{7}$ Ao introduzir uma nova técnica, mais produtiva, enquanto seus concorrentes não o fazem, o capitalista inovador conseguirá produzir bens que têm a mesma soma de trabalho socialmente necessário que antes, porém com menos gasto de trabalho real, produzindo assim bens de menor valor e, consequentemente, menor custo de produção.
} 


\section{Trabalhonecessário}

Issn: 1808 - 799X

ano 12, no $18-2014$

a massa de mais-valia, $\boldsymbol{c}$ o capital constante e $\boldsymbol{v}$ o capital variável. Fica claro, ao se visualizar a fórmula, que qualquer elevação em $\boldsymbol{c}$ diminui o valor de l' (taxa de lucro). Ora, pressionado pelas inexpugnáveis leis da concorrência, o capitalista tem que buscar constantemente aprimoramentos tecnológicos em sua produção, o que constitui necessariamente o aumento da magnitude de seu capital constante. Não obstante, não se olvide que dos elementos do capital, o único que cria valor e mais-valor, por meio da força de trabalho, é o capital variável, o qual, em decorrência da incidência da referida lei, diminui cada vez mais sua participação relativa no capital total $(c+v)$.

Marx, logo no primeiro parágrafo do capítulo XIII, que abre a Parte Terceira do Livro Terceiro, utiliza-se do recurso expositivo de uma hipotética série de equações, na qual busca demonstrar que, com o progressivo decréscimo do capital variável em relação ao constante, a uma taxa de mais-valia constante, esta se expressa em uma taxa de lucro em queda.

Dados o salário e a jornada de trabalho, um capital variável, digamos, de 100 representa determinado número de trabalhadores mobilizados; é o índice desse número. Seja de 100 libras esterlinas o salário de 100 trabalhadores, por uma semana. Se a quantidade de trabalho necessário executada por esses 100 trabalhadores é igual à de trabalho excedente, se, da jornada, a parte destinada a eles, a reproduzir o salário, é igual à destinada ao capitalista, a gerar a mais-valia, produzirão eles o valor global de 200 libras esterlinas, e a mais-valia será de 100 libras esterlinas. Então, seria a taxa da mais-valia $=100 \%$. Entretanto, essa taxa da mais-valia se expressaria, conforme já vimos, em taxas de lucro bem diversas, segundo o tamanho diverso do capital constante c e, por conseguinte, do capital global $\mathrm{C}$, pois é a taxa de lucro $=\mathrm{C}$. Na base de uma taxa de mais-valia de $100 \%$, temos:

Para $c=50$ e v $=100,1^{\prime}=100 / 150=66,67 \% 8$
Para $c=100$ e v $=100,1^{\prime}=100 / 200=50 \%$
Para $c=200$ e $v=100,1^{\prime}=100 / 300=33,33 \%$
Para $c=300$ e v $=100,1^{\prime}=100 / 400=25 \%$
Para $c=400$ e $v=100,1^{\prime}=100 / 500=20 \%$.

Observa ainda o autor que como tal tendência se manifesta não apenas em um setor isolado da economia, mas, se não em todos, pelo menos nos principais,

\footnotetext{
${ }^{8}$ Tendo em conta o uso majoritário, hodiernamente no Brasil, do formato percentual de expressão de proporções, em contraposição ao formato expresso em fração, predominante em outros países e/ou épocas, opta-se, neste trabalho, por aquele, fazendo as devidas adaptações ao texto original de Marx.
} 


\section{Trabalhonecessário}

Issn: 1808 - 799X

ano 12, no $18-2014$

constitui, assim, apenas outra maneira de se expressar o desenvolvimento progressivo da produtividade social do trabalho, elevando continuamente, dessa forma, a composição orgânica média do capital global de uma dada sociedade, levando, assim, a uma tendência de gradual, mas, constante, queda da taxa de lucro geral.

Desmascara-se aqui mais uma "lei" apologeticamente disseminada pela economia burguesa, a de que incrementos de produtividade do trabalho sempre geram aumento dos lucros e, com isso, progresso social, pois, " [...] A taxa de lucro cai não por tornar-se o trabalho mais improdutivo, mas por tornar-se mais produtivo." [...](MARX, 2008, p. 316).

Marx, (2008, p. 288) comprova ainda, matematicamente, na série a seguir, que a taxa de lucro pode cair mesmo com maior extração de mais-valia absoluta.

$$
\begin{aligned}
& \text { I. } \quad 4 c+2 v+2 m ; C=6, l^{\prime}=33,33 \% \\
& \text { II. } 15 c+3 v+3 m ; C=18, l^{\prime}=16,66 \%{ }^{9}
\end{aligned}
$$

Perceba-se que mesmo com o aumento de $50 \%$ (de 2 para 3) da extração de massa de mais-valia dos trabalhadores e do número de trabalhadores empregados, na mesma proporção, houve queda na taxa de lucro, no caso de $50 \%$ (de $33,33 \%$ para $16,66 \%$ ).

O inconveniente (para o capital) paradoxo de uma queda da taxa de lucro, mesmo com a elevação da produção da massa de mais-valia, explica-se pela insuperável contradição encontrada na base do MCP: a contradição entre a vital necessidade que o capital tem de trabalho vivo, despendido pelo trabalhador, o único que cria valor e mais-valor e o imperativo de sua diminuição (relativa ou absoluta) no processo de acumulação de capital, substituindo trabalho vivo por trabalho morto (capital variável por constante).

É possível perceber também o caráter paradoxal da lei da queda tendencial da taxa de lucro no fato de ela indicar graves riscos ao funcionamento do MCP,

\footnotetext{
${ }^{9}$ Atente-se que a taxa de mais-valia, ou taxa de exploração do trabalho, é mantida constante, nas duas séries hipotéticas.
} 


\section{Trabalhonecessário}

Issn: 1808 - 799X

ano 12, no $18-2014$

sinalizando inclusive o próprio colapso do sistema e, ao mesmo tempo, constituir mecanismo que estimula os capitalistas individuais a perseguir avidamente a recuperação de suas antigas massas de mais valia, gerando um vertiginoso crescimento no processo de acumulação de capital, ainda que apenas até certo limite.

\section{Considerações Finais}

À guisa de conclusão, cabe fazer duas relevantes considerações. Primeiro, reafirmar o caráter tendencial, e não fatalista, da lei, insistentemente salientado por Marx, em vários trechos de sua obra magna, a começar pela própria designação que deu a ela, salientando esse caráter, inclusive no título da Parte Terceira do Livro Terceiro ${ }^{10}$. Nesse sentido, um dos capítulos dessa parte, o décimo quarto, trata exatamente dos fatores que representam contratendências ao cumprimento férreo da lei, às quais o capital se aferra obstinadamente para reverter a tendência de queda da taxa de lucro. Dentre alguns, pode-se citar o aumento do grau de exploração do trabalho, a redução dos salários abaixo de seu valor, a baixa de preço dos elementos do capital constante, a "superpopulação relativa" (o exército de reserva de mão-de-obra permite iniciar novos negócios com menor composição orgânica de capital, elevando, assim, a taxa média de lucro), e o comércio exterior (acesso a matérias primas e alimentos mais baratos, provenientes de paises periféricos, de economia primária, barateando o capital constante e aumentando a taxa de mais-valia).

Segundo, observar que a lei da queda tendencial da taxa de lucro constitui apenas mais uma, ainda que a mais emblemática, das manifestações das contradições do MCP, tendo as crises como suas manifestações mais privilegiadas. Diferentemente do que sustentam alguns estudiosos do marxismo, Marx, em seu peculiar método dialético de investigação e exposição, nunca

10 "Lei: tendência a cair da taxa de lucro". (MARX, 2008, p. 277) 


\section{Trabalhonecessário}

Issn: 1808 - 799X

ano 12, no $18-2014$

considerou a referida lei causa da crise, até por não contemplar em seu método, de forma mecânica, as categorias de causa e efeito. Da leitura imanente dos três livros de $O$ Capital depreende-se que as crises do MCP não emanam de causa alguma em particular (ou mesmo em conjunto), mas da própria constituição necessariamente contraditória e autodestruidora do capital.

\section{REFERENCIAS}

ANTUNES, Jadir; BENOIT, Hector. Crise. São Paulo: Ed. Týkle, 2009 MARX, Karl. Grundrisse. São Paulo: Boitempo, 2011.

. O capital. Rio de Janeiro: Civilização Brasileira, 2011a. Livro 1, Vol. 1 . O capital. Rio de Janeiro: Civilização Brasileira, 2011b Livro 1, Vol. 2 . O capital. Rio de Janeiro: Civilização Brasileira, 2003 Livro 2, Vol. 3 . O capital. Rio de Janeiro: Civilização Brasileira. 2008. Livro 3, Vol. 4

Recebido em fevereiro de 2014.

Aprovado em maio de 2014. 